Rev. salud pública. 8 (1): 14-24, 2006

ARTÍCULOSIINVESTIGACIÓN

\title{
Introducing a Clinical-behavioural Scoring System for Children's Oral Hygiene
}

\author{
Carlo E. Medina-Solís , Gerardo Maupomé ${ }^{\text {II }}$, América Segovia-Villanueva ${ }^{\mathrm{III}}$, Alejandro \\ J. Casanova-Rosado ${ }^{I V}$, Ana A. Vallejos-Sánchez ${ }^{\mathrm{V}}$ and Juan F. Casanova-Rosado ${ }^{\mathrm{VI}}$

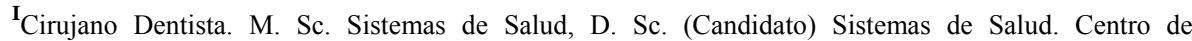 \\ Investigación en Sistemas de Salud del Instituto Nacional de Salud Pública. Cuernavaca, México. E- \\ mail:cemedinas@yahoo.com. \\ ${ }^{\text {II }}$ Cirujano Dentista. Ph.D. Public Health, M. Sc. Experimental Pathology, Diploma in Dental Public \\ Health from the Royal College of Surgeons of England. Oral Health Research Institute, Indiana \\ University/Purdue University at Indianapolis School of Dentistry. Indianapolis, Indiana., USA. E-mail: \\ gmaupome@iupui.edu. \\ III Cirujana Dentista. M. Sc. Ciencias Odontológicas. Instituto Mexicano del Seguro Social y Facultad de \\ Odontología de la Universidad Autónoma de Campeche. Campeche, México. \\ E-mail: america.segovia@imss.gob.mx. \\ ${ }^{\text {IV }}$ Cirujano Dentista, Especialista en Endodoncia. M. Sc. Ciencias Odontológicas. Facultad de Odontolo- \\ gía de la Universidad Autónoma de Campeche. Campeche, México. \\ E-mail: ajcasano@uacam.mx.

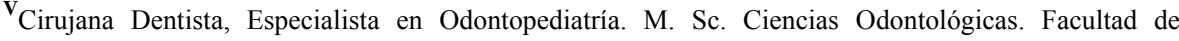 \\ Odontología de la Universidad Autónoma de Campeche. Campeche, México. \\ ${ }^{\text {VI }}$ irujano Dentista, Especialista en Ortodoncia. M. Sc. Ciencias Odontológicas. Facultad de Odontología \\ de la Universidad Autónoma de Campeche. Campeche, México. E-mail: juanf_casanova@yahoo.com.mx
}

Received on $16^{\text {th }}$ July 2005/reviewed on $24^{\text {th }}$ December 2005/Accepted $4^{\text {th }}$ February 2006

\section{ABSTRACT}

Objectives Developing and testing a clinical-behavioural scoring system for assessing children's oral hygiene.

Materials and Methods One clinical variable (the presence of dental plaque, measured using Silness and Löe's index) and one behavioural variable (self-reported tooth brushing frequency) were combined into secondary data analysis of research databases for 3-6-year-olds and 6-13-year-olds in a Mexican community. The combined scoring is an ordinal scale that depicts suitable, moderate and inadequate hygiene. Blinded dental examiners also collected dmft/DMFT data in standardised conditions. Data was analysed 
with Spearman's rho, Kruskall-Wallis, non-parametric tests for trends and Pearson's $x^{2}$ tests.

Results 1303 children aged 3-6 years old and 1,644 children aged 6-13 years old participated in the study. Clear relationships existed between the combined scoring system and dmft $(p<0.01)$ and between the scoring system and DMFT $(p<0.01)$, suggesting that the combined clinical-behavioural scoring system is a reasonably accurate measurement of the relationship between caries experience and oral hygiene in children in the given setting.

Conclusions The combined clinical-behavioural scoring system is a simple, easy-to-use tool that incorporates clinical and behavioural data commonly found in dental systems. Whether the clinical-behavioural scoring system can be generalised remains to be established

Key Words: Oral hygiene, children, preschool, schools, Mexico (source: $\mathrm{MeSH}, \mathrm{NML}$ ).

\section{RESUMEN}

Sistema de puntaje clínico-conductual para la evaluación de la higiene bucal

Objetivos Desarrollar un sistema de puntaje clínico-conductual para medir la higiene bucal en niños.

Material y Métodos La investigación se realizó en dos etapas: 1) detección y selección de componentes de la higiene bucal, y 2) evaluación de la asociación con la caries dental. Una variable clínica (presencia de placa dentobacteriana usando el índice de Silness y Löe) y una variable conductual (reporte de la frecuencia de cepillado) fueron combinadas en un análisis secundario de dos bases de datos de investigaciones epidemiológicas en niños de 3-6 años y de 6-13 años de edad en una comunidad mexicana. El puntaje combinado es en una escala ordinal que describe higiene bucal adecuada, moderada e inadecuada. Los examinadores también colectaron los índices ceod/CPOD. Los datos se analizaron con las pruebas de rho de Spearman, Kruskall-Wallis, no-paramétrica para tendencias, y $x^{2}$ de Pearson.

Resultados 1303 niños de 3-6 años de edad, y 1644 niños de 6-13 años de edad participaron en los estudios. Se encontró una clara relación entre el sistema y el índice ceod $(p<0.01)$, y entre el sistema y el índice CPOD $(p<0.01)$, sugiriendo que este sistema es una medida adecuada de la higiene bucal en esta población.

Conclusión El sistema de puntaje clínico-conductual para medir la higiene bucal es una herramienta simple y fácil de usar que incorpora datos clínicos y conductuales comúnmente encontrados en investigaciones dentales. El potencial del sistema de puntaje clínico-conductual para medir la higiene bucal para usarse en otras poblaciones necesita establecerse en estudios subsecuentes. 
Palabras Clave: Higiene bucal, niños, preescolar, escolares, México (fuente: DeCS, BIREME).

7 ooth decay is one of the most apparent public health problems around the world, in addition to periodontal disease. It affects all ages, but appears to preferentially attack younger age groups in less developed countries (LDC), being partially modulated by economic development stage and lifestyle factors in any given country (1-6).

A young child's dental environment is complicated by the fact that a mother's beliefs and practices affect her child's oral condition (7). Given that dental plaque is considered to be an agent of aetiological dental caries and periodontal disease, several studies in humans have shown that controlling plaque is a key factor in preventing dental caries, gingivitis, and periodontitis and can be used for assessing oral hygiene. Describing oral hygiene habits is crucial as oral health promotion focuses on improving oral health behaviour. Brushing teeth regularly is the most important oral health habit. The effectiveness of brushing teeth, however, depends on motivation, hygiene instruction, oral hygiene aids and manual dexterity. Mothers/guardians reporting their children's patterns of brushing teeth have been used for assessing oral hygiene (8). Kalsbeek and Verrips (9) proposed a score for oral hygiene habits consisting of brushing a child's teeth and fluoride tablet and toothpaste use. While such approaches appear to be sound, they may not relevant for LDC settings. Vallejos (10) has demonstrated that all children who brush their teeth in Mexico use fluoridated toothpaste; it thus follows that fluoride toothpaste exposure is universal in Mexican children who brush their teeth. This differs from Kalsbeek and Verrips' (9) scoring system because fluoride tablets are not used in Mexico; public health fluoridation hinges solely upon domestic salt fluoridation.

Measurement tools have generally been designed to evaluate one component of the overall health situation in the mouth (e.g. dental plaque, presence and severity of gingivitis, cross-sectional tooth loss status vs. number of teeth present, presence/absence of tooth decay and severity of tooth decay). An index combining more than one component could better predict tooth decay than indices relying on single-component appraisals given the complex nature of the factors mentioned above and the obscure interactions leading to clinically significant stages of tooth decay. The Extent and Severity Index (ESI) is an example of a combined index approach (11). Innovative in its conceptualisation, the ESI contemplates mean severity of attachment loss at all affected sites in the mouth and also includes the proportion of affected periodontal sites. The two values offered in ESI thereby lead to more infor- 
mation being obtained; however, as two values are derived (a mean reading given in millimetres the other as a proportion), this undermines its simplicity (one of the ideal features of any epidemiological index).

No real consideration is given to factors which should be represented in oral hygiene, such as oral hygiene customs or the presence of plaque. Both these features make important contributions to signalling tooth decay either as surrogate markers of fluoridated toothpaste exposure or as indicators of the degree of importance ascribed to dental fitness and oral health. Designs have resorted to the single-component approach when indices have been used for ascertaining the presence of dental plaque or oral hygiene customs. The present study sought to develop and test whether a scoring system combining components for oral hygiene was simple to describe, use and interpret in terms of oral hygiene's contribution to tooth decay. The two single components combined were the presence of dental plaque in primary and permanent teeth in children aged 3 to 13 and children's patterns of brushing teeth as reported by their mothers/guardians.

\section{MATERIALS AND METHODS}

The investigation was carried out in two stages using different methods: detecting and selecting oral hygiene components and evaluating association with dental caries.

Selecting the scoring system's component factors

The presence of dental plaque and tooth brushing pattern were selected for being combined in the oral hygiene clinical-behavioural scoring system. These factors were chosen by research team consensus following discussion concerning which factors influencing oral hygiene status would most accurately reflect overall status while at the same time preserving both ease of scoring system use and straightforward procedure for acquiring information. Factor content was taken into account during the selection process (in terms of contrasting diverse dimensions relevant to oral hygiene) resulting in salient dimensions being clinical and behavioural. The biological plausibility of factors affecting oral hygiene and the feasibility of administering the scoring system were also considered, for practical aspects and ensuring that users found it acceptable and understandable (12).

The importance ascribed to these assumptions may not be generalised to other settings. These two components were selected as the presence of dental plaque has often been used as an indicator of individual oral hygiene profi- 
ciency. The detectable quantity, however, is only a relative representation of oral hygiene customs because it depends on both plaque control measures and the oral environment's support for bacterial proliferation. Detecting dental plaque is easy, inexpensive, does not cause discomfort and has long been a cornerstone of school surveys in Campeche. Tooth-brushing patterns are usually elicited in school- or household-based oral health surveys. While providing simple and accessible data for exposure to fluoridated toothpaste, tooth-brushing patterns may be misrepresented by a mother/guardian if it is felt that the child or family should conform to a health behaviour norm. It may be argued that a two-component scoring system offers advantages over one relying on a single component (tooth brushing patterns or dental plaque) since only partial information may be gathered or biased information included (13).

Description of study population

Campeche is a large coastal community on the western shore of the Yucatan Peninsula in the Gulf of Mexico. It is the capital city of the State of Campeche. The present study made secondary data analysis of existing research databases; these databases pertained to two cross-sectional epidemiological studies on tooth decay in children from Campeche $(14,15)$. The first study (3-6 study) was carried out on children aged 3 to 6 living in the community who were regularly attending pre-school and day-care facilities. The second study (6-13 study) targeted children aged 6-13 attending elementary schools in Campeche. Participants were screened as part of a preventative programme run by state and federal health authorities. The 3-6 study had 1,303 participants and the 6-13 study, 1,644. Both studies adhered to the recommendations laid down by the Institutional Review Board and to current Universidad Autónoma de Campeche's Dental Faculty Infection Control practice.

\section{Data collection procedure}

Study participants were examined by a dentist at the nursing station of the facility/school they attended. Four examiners in the 3-6 study and three in the 6-13 study were trained by a qualified supervisor (kappa coefficients ranged from 0.83 to 0.92 ). Clinical variables (tooth decay and dental plaque) were compiled via oral examination using a flat dental mirror in natural light (16). Clinical examiners were blinded to questionnaire results and did not take part in administering the survey. Clinical examiners collected $\mathrm{dmft} / \mathrm{DMFT}$ and dental plaque data without being aware of the proposed combined scoring system. 
Caries prevalence in primary teeth was established by the proportion of participants who had dmft $>0$. Prevalence in permanent teeth was established by the percentage of participants having DMFT $>0$.

The Silness and Löe modified index was used for measuring dental plaque; this index's operational definition was used and all tooth surfaces (buccal, lingual, mesial, and distal) were assessed. Plaque was considered present if identifiable on more than $20 \%$ of teeth and absent if plaque could not be identified on at least $20 \%$ of teeth. Teeth were not brushed before examination. Individual participants did not know their exam time to avoid biasing their plaque control.

Tooth brushing patterns were obtained from a structured questionnaire which had been developed, tested and used as a part of large-scale epidemiological research; it was administered to the children's mothers/guardians who completed it themselves.

The present study used only information pertaining to children's toothbrushing (on their own or with help). Self reported data was not independently corroborated for accuracy or reproducibility. The values were recoded as described in the analysis section.

Data management and analysis

The oral hygiene combined clinical-behavioural scoring system was constructed as follows. A clinical (the presence of dental plaque) and behavioural (tooth brushing frequency) variable were used. Past reports were consulted to determine the public's willingness to volunteer information on tooth brushing patterns (17-20) and how adaptable plaque measurement would be to epidemiological assessment in various population groups throughout Mexico (16,19,21). Following consensus being reached within the research group, tooth brushing frequency and plaque control were then categorised. Suitable oral hygiene referred to children who had no detectable plaque and their mothers/guardians indicated that they had their teeth brushed daily (at least once per day). Moderate oral hygiene had two scenarios: children having no detectable plaque and a report indicating that teeth were brushed occasionally or never, and children with plaque whose mothers/guardians asserted that children had their teeth brushed daily (at least once per day). Inadequate oral hygiene referred to children who had detectable plaque and their mothers/guardians indicated that teeth were brushed only occasionally or never. 
Combined scoring system values and constituting variables were weighted separately: 0 for a positive feature and 1 for a negative feature. Final weighting was structured so that daily brushing (at least once a day) was 0 and occasional or no brushing was 1 . No detectable plaque was 0 and 1 was scored for plaque being present (assuming exchangeable values from dichotomic to ordinal scales). Combined scoring system values were also simple on an ordinal scale $(0=$ suitable, $1=$ moderate and $2=$ inadequate $)$.

Two forms of validity were assessed: apparent (qualitative evaluation of known scoring system components and coarser aspects) and content validity (qualitative evaluation focusing on complete measurement of a characteristic (i.e. oral hygiene) which it is purported to ascertain). Criteria validity was not evaluated as it would have entailed using gold standard or index standardisation; this would have allowed presenting quantifiable operating characteristics, but no current criterion incorporates every dimension of oral hygiene (12). Validation was external, based on contrasting the combined oral hygiene combined clinical-behavioural scoring system with other variables (22); it would have been validated if its values were associated in a biologically plausible way with a separate variable (i.e. tooth decay).

Data was stored in electronic databases and analysed using STATA 7. Variables were first examined for distribution using univariate analysis. The statistical tests employed were the Kruskall-Wallis test (to ascertain whether $\mathrm{dmft}$ and DMFT median values differed between combined scoring system categories), a non-parametric test for trends (to establish dmft and DMFT changes) and Pearson's $\chi^{2}$ test (to determine whether there were differences between tooth decay prevalence values).

\section{RESULTS}

The 3-6 study involved 1303 children (mean age 4.36 $\pm 0.79 ; 48.3 \%$ were female); the 6-13 study involved 1,644 (mean age 9.06 $\pm 2.02 ; 49.2 \%$ were female).

Table 1 presents the single-component variables with values from the two studies. About $41 \%$ of all participants examined in the two studies had no dental plaque. Differences between the 3-6 and 6-13 studies were evident in terms of tooth brushing patterns, $71.5 \%$ of the younger subjects engaging in daily brushing ( $28.5 \%$ only occasionally or never) and an even distribution between older children who reportedly daily brushing and those who occasionally or never brushed. 
Table 1. Dental plaque and tooth brushing frequency distribution for children

\begin{tabular}{ccc}
\multicolumn{3}{c}{ in the 3-6 and 6-13 studies } \\
\hline Variable & $\begin{array}{c}3-6 \text { study } \\
\mathrm{n}=1,303(\%)\end{array}$ & $\begin{array}{c}6-13 \text { study } \\
\mathrm{N}=1,644(\%)\end{array}$ \\
\hline Dental plaque & & \\
Not detectable & $547(42.0)$ & $681(41.4)$ \\
Present & $756(58.0)$ & $963(58.6)$ \\
Tooth brushing & & \\
Daily & $932(71.5)$ & $818(49.8)$ \\
Occasionally/Never & $371(28.5)$ & $826(50.2)$ \\
\hline
\end{tabular}

Contrasting caries and the scoring system in the 3-6 study was limited to primary dentition; the 6-13 study contrasted the combined scoring system with both primary and permanent dentition. 3-6 study data revealed a significant difference for median $\mathrm{dmft}$ values for children in different combined scoring system categories $(\mathrm{p}<0.001)$ (Table 2$)$. A non-parametric test for trends supported a clear inverse relationship between combined scoring system and dmft values $(p<0.01)$. Prevalence figures for tooth decay for combined scoring system categories reflecting suitable, moderate and inadequate hygiene were $32.1 \%, 47.4 \%$ and $56.0 \%$, respectively $\left(\chi^{2}\right.$ test, $\left.\mathrm{p}<0.001\right)$ (Table 2).

Table 2. Participants classified into the combined index's categories across two broad $\mathrm{dmft}$ levels ( $\mathrm{dmft}=0$ and $\mathrm{dmft}>0$ ) in the 3-6 study

\begin{tabular}{ccccc} 
& & & & \\
& Suitable & Moderate & Inadequate & Total \\
\hline $\mathrm{dmft}=0$ & 277 & 349 & 102 & 728 \\
$\mathrm{dmft}>0$ & 131 & 314 & 130 & 575 \\
Total & 408 & 663 & 232 & 1,303 \\
\hline $\mathrm{x}^{2}=48.31 ; \mathrm{p}=0.001$, Kruskall-Wallis test $=39.74 ; \mathrm{p}=0.0001$, Non-parametric test for trends $\mathrm{z}=6.28 ; \mathrm{p}=0.001$
\end{tabular}

Contrasting 6-13 study data showed that there were significant differences across median dmft values $(p<0.001)$ and DMFT values $(p<0.05)$ for children classified into different combined scoring system categories $(\mathrm{p}<0.001)$ (Table 3). A non-parametric test for trends supported a clear inverse relationship between the combined scoring system and $\mathrm{dmft}$ and between the scoring system and DMFT $(p<0.01)$. Prevalence figures for tooth decay in primary dentition for combined scoring system categories reflecting suitable, moderate and inadequate hygiene were $65.6 \%, 74.7 \%$ and $77.5 \%$, respectively $\left(\chi^{2}\right.$ test, $\left.\mathrm{p}<0.01\right)$ and $42.9 \%, 49.3 \%$ and $54.4 . \%$ in permanent dentition, respectively $\left(\chi^{2}\right.$ test, $\left.p<0.01\right)$ (Table 3$)$. 
Table 3. Participants classified into each combined index category across two broad dmft levels ( $d m f t=0$, and $d m f t>0)$ and two broad DMFT levels (DMFT $=0$ and DMFT $>0$ ) in the 6-13 study

\begin{tabular}{ccccc}
\hline & Suitable & Moderate & Inadequate & Total \\
\hline $\mathrm{dmft}=0$ & 98 & 150 & 97 & 345 \\
$\mathrm{dmft}>0$ & 187 & 442 & 335 & 964 \\
Total & 285 & 592 & 432 & $1,309^{*}$ \\
\hline DMFT $=0$ & 213 & 380 & 236 & 829 \\
DMFT $>0$ & 160 & 370 & 281 & 811 \\
Total & 373 & 750 & 517 & $1,640^{* *}$ \\
${ }^{* *} \mathrm{x}^{2}=13.17 ; p=0.001$, Kruskall-Wallis test=24.72; $\mathrm{p}=0.0001$, Non-parametric test for trends $z=3.34 ; p=0.001$ \\
$\mathrm{x}^{2}=11.38 ; p=0.003$, Kruskall-Wallis test=6.22; $p=0.0447$, Non-parametric test for trends $z=3.35 ; p=0.001$
\end{tabular}

\section{DISCUSSION}

This report presents a simple, combined clinical-behavioural scoring system for oral hygiene in children aged 3-13 by maximising information concerning two components of oral hygiene (detectable levels of dental plaque and reported patterns of tooth brushing). The importance ascribed to each variable used in the oral hygiene combined clinical-behavioural scoring system and how variables were used in constructing the combined scoring system cannot be generalised to other settings. The combined scoring system was simple to describe, use and interpret in Campeche; however, its effect size was somewhat small, suggesting that the scoring system does not offer vast discrimination capabilities. Differences were significant and intuitive, but not large.

Exposure to sucrose "hits" could be incorporated into the combined scoring system as it is an important aspect of cariogenic conditions in the mouth as well as (or instead of) one of the two components used. Most of Mexico's epidemiologic data is collected by personnel trained in methods lacking epidemiological rigour. Information regarding simpler items (i.e. identifying plaque and tooth brushing patterns) should thus be collected rather than attempting to retrain the average dental student or dentist not to diagnose, manage and treatment-plan everything resembling tooth decay $(23,24)$.

There is a dearth of information regarding oral health and disease trends in LDCs (1-3). A good way of stretching available public funds for assessing the population's dental health lies in using tools aimed at maximising the information accrued by measuring easily accessible features that can be measured by publicly-acceptable methods and are already part of survey protocol; the oral hygiene combined clinical-behavioural scoring system could be a step in the right direction. The next stage in establishing whether this system 
can be applied to settings other than Campeche is to perform similar validation exercises in other locales. Future caries' incidence assessment should be used for testing whether the combined scoring system can identify longitudinal change. Such studies could provide more informative results by incorporating different cut-off levels within the combined scoring system and study group caries' experience as well as adding internal and external approaches for validating the scoring system.

Acknowledgments. This work was partly supported by a grant from the National Council of Science and Technology (CONACyT-166266)

\section{REFERENCES}

1. Sheiham A. Dental caries in underdeveloped countries. In: Guggenheim B, ed. Cariology Today. Basel: Karger Press; 1984:33-9.

2. Beltrán-Aguilar Estupiñán-Day S, Báez R. Analysis of prevalence and trends of dental caries in the Americas between 1970s and 1990s. Int Dent J 1999;49:322-329.

3. Miura H, Araki Y, Haraguchi K, Arai U, Umenai T. Socioeconomic factors and dental caries in developing countries: a cross national study. Soc Sci Med 1997;44:269-272.

4. Maupomé G. "Who is Filling What?" The contrast between the oral health situation and human health resources in Mexico. Critical Public Health 2000;10:153-166.

5. Diehnelt DE, Kiyak HA. Socioeconomic factors that affect international caries levels. Community Dent Oral Epidemiol 2001;29:226-233.

6. Herrera M, Medina-Solis CE, Rosado-Vila G, Minaya-Sánchez M, VallejosSánchez A, Casanova-Rosado J. Prevalencia, severidad de caries y necesidades de tratamiento en preescolares de una comunidad suburbana de Campeche-2001. Bol Med Hosp Infant Mex 2003;60:189-196.

7. Chan SCL, Tsai JSJ, King NM. Feeding and oral hygiene habits of preschool children in Hong Kong and their caregivers' dental knowledge and attitudes. Int J Paediatr Dent 2002;12:322-331.

8. Martens L, Vanobbergen J, Leroy R, Lesaffre E, Declerk D. Variables associated with oral hygiene levels in 7-years-olds in Belgium. Community Dent Health 2004;21:4-10.

9. Kalsbeek H, Verrips GH. Consumption of sweet snacks and caries experience of primary school children. Caries Res 1994;28:477-483.

10. Vallejos-Sánchez AA, Medina-Solís CE, Casanova-Rosado JF, Maupomé G, Minaya-Sánchez M, Pérez-Olivares S. Dental fluorosis in cohorts born before, during and after the national salt fluoridation program in a community in Mexico. Acta Odontol Scand 2006;64: in press.

11. Carlos JP, Wolfe M, Kingman A. The extent and severity index: a simple method for use in epidemiologic studies of periodontal disease. J Clin Periodontol 1986;13:500-505. 
12. Velarde-Jurado E, Avila-Figueroa C. Consideraciones metodológicas para evaluar la calidad de vida. Salud Pública Méx 2002;44:448-463.

13. Hernández-Ávila M, Garrido F, Salazar-Martínez E. Sesgos en estudios epidemiológicos. Salud Pública Méx 2000;42:438-436.

14. Segovia-Villanueva A, Estrella-Rodríguez R, Medina-Solís CE, Maupomé G. Severidad de caries en preescolares bajo un programa de odontología preventiva. Rev Salud Pública (Bogotá) 2005;7:56-69.

15. Casanova-Rosado AJ, Medina-Solís CE, Casanova-Rosado JF, Vallejos-Sánchez AA, Maupomé G, Ávila-Burgos L. Dental caries and associated factors in Mexican schoolchildren aged 6-13 years. Acta Odontol Scand 2005;63:245-251.

16. World Health Organisation. Oral Health Surveys. Basic Methods. $3^{\text {rd }}$ edition. Geneva; 1987.

17. Maupomé-Carvantes G, Borges-Yáñez SA, Ledesma-Montes C, Herrera-Echauri R, Leyva-Huerta ER, Navarro-Alvarez A. Prevalencia de caries en zonas rurales y periurbanas marginadas. Salud Pública Méx 1993;35:357-367.

18. Maupomé G, Borges-Yáñez SA, López-Pérez R, Ramírez-Mireles LE, Díez-deBonilla FJ. Relationship between socio-economic level and oral health status in an elderly population in Mexico City. Archiv Odontoestomatol Prev Com 1998;14:647-656.

19. Maupomé G. An introspective qualitative report on dietary patterns and elevated levels of dental decay in a deprived urban population in Northern Mexico. ASDC J Dent Child 1998;65:276-285.

20. Maupomé G, Borges A, Ramírez LE, Díez-de-Bonilla J. Perceptions of tooth loss and periodontal problems in an independent elderly population. Content-analysis of interview discourse. J Cross Cult Gerontol 1999;14:43-63.

21. Dufoo S, Maupomé G, Díez de Bonilla J, Hernández-Guerrero JC. Caries experience and treatment-experience in a selected patient population in México City. Community Dent Oral Epidemiol 1996;24:298-299.

22. Bronfman M, Guiscafré H, Castro V, Castro R, Gutiérrez G. Strategies for improving the therapeutic patterns used in acute diarrhoea in primary medical care units. II. The measurement of inequality: a methodological strategy, analysis of the socioeconomic features of the sample. Arch Med Res 1988;19:351-360.

23. Maupomé G, Sheiham A. Clinical decision-making in Restorative Dentistry. Content-analysis of diagnostic thinking processes and concurrent concepts used in an educational environment. Eur J Dent Educ 2000;4:143-152.

24. Maupomé G, Sheiham A. Explanatory models in the interpretations of clinical features of dental patients within a university dental education setting. Eur J Dent Educ 2002;6:2-8. 